\title{
As ideias do poder e o poder das ideias: o Banco Mundial como ator político-intelectual
}

\author{
JOÃO MÁRCIO MENDES PEREIRA \\ Universidade Federal Rural do Rio de \\ Janeiro, Seropédica, RJ, Brasil
}

Os expertos do FMI e do Banco Mundial parecem ter todos os atributos de uma autoridade internacional. Não obstante, abrigam certas dúvidas a respeito do tipo de poder com que contam. Dentro do âmbito de Washington, eles ocupam uma posição paradoxal. De um lado, encontram-se perto dos lugares onde as decisões cruciais são tomadas, mas, de outro, a dita proximidade somente ressalta a sua própria falta de autonomia nos jogos de poder sobre os quais têm um controle precário. Dezalay \& Garth, 2005, p. $137^{1}$

Deve ser incluida como parte do sistema estadunidense a rede global de organizações especializadas, particularmente as instituições financeiras "internacionais". O Fundo Monetário Internacional (FMI) e o Banco Mundial são considerados representantes dos interesses "globais" e de circunscrição global. Na realidade, porém, são instituições fortemente dominadas pelos Estados Unidos e suas origens remontam a iniciativas estadunidenses.

BrzezInski, 1998, p. 36-37

1 As traduções são do autor. 


\section{A lição é clara: aconselhamento é tão importante quanto dinheiro. $E$ um dos pontos mais fortes do Banco é que o nosso conselho é independente. Os governos confiam em nós. Wolfensohn, 1995, p. 17}

Em operação desde 1946, o Banco Mundial ${ }^{2}$ tornou-se uma organização imensa e de enorme complexidade, muito diferente daquela imaginada e acordada em 1944 na conferência de Bretton Woods, patrocinada pelo governo norte-americano. Em todos os níveis em que com o tempo passou a atuar - financiamento de projetos e programas, diálogo com governos nacionais e subnacionais e assistência técnica ao setor público, pesquisa econômica, liderança sobre outros organismos multilaterais e coordenação de iniciativas internacionais -, o Banco age de maneira prescritiva a respeito do que os governos devem fazer em matéria de políticas públicas de desenvolvimento.

A amplitude com que o faz também é significativa, abarcando desde educação, saúde, habitação, energia, agropecuária, política econômica, transporte, infraestrutura, desenvolvimento urbano e rural, indústria, comércio, meio ambiente e administração pública, até a reconstrução nacional em países pós-conflito e a assistência internacional ao desenvolvimento. Por sua vez, dentro de cada uma dessas áreas, o Banco atua em praticamente todos os âmbitos de especialização. Em outras palavras, não há política de desenvolvimento que não seja objeto da ação financeira e não financeira do Banco.

A subida do Banco à condição de organização internacional relevante decorreu de contingências históricas, de decisões institucionais e, fundamentalmente, da supremacia norte-americana. O Banco é, em larga medida, uma criação dos Estados Unidos (EUA), tendo sido forjado como parte da rede de poder infraestrutural externo estadunidense (Wade, 1997).

As relações com os EUA foram decisivas para a definição da direção política, da estrutura operacional, das pautas de empréstimo e das práticas institucionais do Banco. Sempre na condição de maior acionista e único com poder de veto na instituição, os EUA beneficiaram-se largamente da sua ação econômica e política, mais que qualquer outro grande acionista, tanto em curto como em longo prazo (Gwin, 1997).

2 O Grupo Banco Mundial (GBM) é constituído por sete organizações com diferentes mandatos, gravitação política, estruturas administrativas e instâncias de decisão. São elas: Banco Internacional para a Reconstrução e o Desenvolvimento (BIRD), criado em 1944; Associação Internacional de Desenvolvimento (AID), criada em 1960; Corporação Financeira Internacional (CFI), de 1956; Centro Internacional para Conciliação de Divergências em Investimentos (CICDI), de 1966; Agência Multilateral de Garantias de Investimentos (AMGI), de 1988; Instituto de Desenvolvimento Econômico (IDE), de 1955, renomeado de Instituto do Banco Mundial (IBM) em 2000; e Painel de Inspeção, criado em 1993. O chamado "Banco Mundial" é formado apenas pelo BIRD e pela AID, mas mantém estreita articulação com o conjunto do GBM, à exceção, em parte, do Painel de Inspeção. 
Essa estranha espécie de banco sempre explorou a sinergia entre empréstimos e pensamento econômico para ampliar a sua influência e institucionalizar a sua pauta de políticas em âmbito internacional. Pesquisa recente mostrou como o Banco age, desde as suas origens, ainda que de diferentes formas, como um ator político, intelectual e financeiro, e o faz em virtude de sua condição singular de emprestador, formulador e articulador de políticas e veiculador de ideias - produzidas pelo mainstream anglo-saxônico e disseminadas por ele ou produzidas por ele, em sintonia com o mainstream - sobre o que fazer, como e para quem em matéria de desenvolvimento capitalista. É precisamente por meio dessa combinação singular de papéis e funções que o Banco opera.

Desde o início de sua história, o Banco promove inúmeras articulações formais e informais com atores bilaterais e multilaterais públicos e privados muito variados. Com frequência, assume nessas iniciativas uma posição de liderança intelectual. Tais articulações tornam possível ao Banco viabilizar a sua influência e dilatar imensamente o seu raio de ação. A Tabela 1 oferece um panorama resumido das organizações financeiras internacionais associadas formalmente ao Banco em meados de 2010.

Tabela 1 - Organizações financeiras internacionais associadas ao Banco Mundial (30 jun. 2010)

\begin{tabular}{l}
\hline \multicolumn{1}{c}{ Bancos multilaterais de desenvolvimento } \\
\hline Banco de Desenvolvimento Asiático \\
\hline Banco de Desenvolvimento Africano \\
\hline Banco Europeu para a Reconstrução e o Desenvolvimento \\
\hline Banco Interamericano de Desenvolvimento
\end{tabular}

\section{Instituicões financeiras multilaterais}

Comissão Europeia

Banco Europeu de Investimentos

Fundo Internacional de Desenvolvimento Agrícola

Banco Islâmico de Desenvolvimento

Fundo Nórdico de Desenvolvimento

Banco Nórdico de Investimentos

Fundo da OPEP* para o Desenvolvimento Internacional

\section{Bancos sub-regionais}

Corporação Andina de Fomento

Banco de Desenvolvimento do Caribe

Banco Centroamericano de Integração Econômica

Banco de Desenvolvimento da África Oriental

Banco de Desenvolvimento da África Ocidental

Fonte: Disponível em: <http://go.worldbank.org/QNBYD9J670>. Acesso em: 27 mar. 2011.

Elaboração do autor.

* Organização dos Países Exportadores de Petróleo. 
O Banco também patrocina a criação de diversas parcerias multilaterais e se integra a outras tantas já existentes. A Tabela 2 lista as principais delas em curso em meados de 2010.

\section{Tabela 2 - Principais parcerias multilaterais do Banco Mundial (30 jun. 2010)}

\begin{tabular}{|c|c|}
\hline Parcerias & Sinopse \\
\hline $\begin{array}{l}\text { Grupo Consultivo para } \\
\text { a Pesquisa Agrícola } \\
\text { Internacional (CGIAR) }\end{array}$ & $\begin{array}{l}\text { Criado em 1971, tem como membros } 47 \text { países, } 4 \text { copatrocinadores e } \\
\text { outros } 13 \text { organismos internacionais. Abrange uma rede de } 15 \text { centros } \\
\text { internacionais de pesquisa agronômica e mais de } 8 \text { mil cientistas e } \\
\text { profissionais diversos em mais de } 100 \text { países, que trabalham em cola- } \\
\text { boração com centenas de organizações não governamentais (ONGs) } \\
\text { e empresas privadas. }\end{array}$ \\
\hline $\begin{array}{l}\text { Fundo Global para o } \\
\text { Meio Ambiente (GEF) }\end{array}$ & $\begin{array}{l}\text { Parceria global entre } 182 \text { países, organizações internacionais, ONGs } \\
\text { e empresas privadas. Funciona como mecanismo financeiro para acor- } \\
\text { dos multilaterais na área de meio ambiente. É o principal financiador } \\
\text { mundial de projetos nessa área. Desde } 1991 \text { forneceu US } \$ 9,2 \text { bilhões } \\
\text { em créditos e alavancou US } \$ 40 \text { bilhões em cofinanciamentos para } \\
\text { mais de } 2.700 \text { projetos em } 165 \text { países. Por meio do seu Programa de } \\
\text { Pequenas Doações, também fez mais } 12 \text { mil operações financeiras a } \\
\text { ONGs, que totalizaram US } \$ 495 \text { milhões. }\end{array}$ \\
\hline
\end{tabular}

Grupo Consultivo para Assistência aos Mais Pobres (CGAP)

Iniciativa para a Reforma e o Fortalecimento do Setor Financeiro (FIRST)

\section{Fundo Tipo para Reduzir as Emissões de Carbono}

Educação para Todos

Programa Conjunto das Nações Unidas sobre HIV/AIDS

Associação Mundial para a Água (GWP)
Parceria entre agências bilaterais e multilaterais de desenvolvimento, bancos multilaterais de desenvolvimento, fundações privadas e instituições financeiras multilaterais. Tem como missão construir sistemas de microcrédito para populações de baixa renda.

Lançado em 2002 por agências bilaterais do Canadá e da Europa em parceria com o Fundo Monetário Internacional (FMI) e o Banco Mundial (responsável pela sua administração), tem como missão promover o fortalecimento de sistemas financeiros abertos e diversificados em países de renda baixa e média, em particular na África. Foi estendida até 2012 com uma carteira de US\$100 milhões.

Parceria entre 17 corporações privadas e 6 países; desde 2000 funciona sob a administração do Banco Mundial. Tem o propósito de promover mercados para o sequestro de carbono.

Iniciada após a Conferência de Jomtien (Tailândia), em 1990, é coordenada pela Organização das Nações Unidas para a Educação, a Ciência e a Cultura (UNESCO) e tem como objetivo principal promover a universalização da educação básica. Tem relação direta com os "Objetivos de Desenvolvimento do Milênio" da Organização das Nações Unidas (ONU), aprovados por quase 200 países.

Envolve a articulação de diversas organizações do sistema ONU, empresas privadas, fundações privadas e ONGs.

Criada em 1996 por iniciativa do Banco Mundial junto com o Programa das Nações Unidas para o Desenvolvimento (PNUD) e a Agência de Cooperação Sueca de Desenvolvimento Internacional, envolve diversas agências públicas, empresas privadas, organizações profissionais e instituições multilaterais. Tem a missão de promover ou reformar sistemas de regulação e administração hídrica. É financiada pelo Canadá, Dinamarca, Comissão Europeia, Finlândia, França, Alemanha, Holanda, Noruega, Suécia, Espanha, Suíça, Reino Unido e EUA. 


\begin{tabular}{ll}
\hline \multicolumn{1}{c}{ Parcerias } & \multicolumn{1}{c}{ Sinopse } \\
\hline $\begin{array}{l}\text { Iniciativa para os Países Pobres } \\
\text { Muito Endividados (PPME) }\end{array}$ & $\begin{array}{l}\text { Lançada em 1996 em parceria com o FMI, envolve a redução da dívi- } \\
\text { da externa multilateral condicionada à execução de políticas de ajus- } \\
\text { tamento estrutural e setorial. }\end{array}$ \\
$\begin{array}{l}\text { Programa de pequenas doações administrado pelo Banco Mundial com } \\
\text { o apoio de inúmeras organizações, entre as quais a Fundação Bill \& }\end{array}$ \\
Melinda Gates e o Fundo Global para o Meio Ambiente. Financia pro- \\
jetos sociais variados, cujos proponentes concorrem entre si anualmente.
\end{tabular}

Iniciativa de Recuperação de Ativos Roubados (StAR)

\section{Serviço de Assessoria em Investimento Estrangeiro (FIAS)}

Fundos de Investimento Climático (CIF)

\section{Parceria em Estatística para o Desenvolvimento do Século XXI (PARIS21)}

Fundo Fiduciário de Resposta à Crise de Preços de Alimentos (FPCR)
Lançada em setembro de 2007 em parceria com o Escritório de Drogas e Crime das Nações Unidas, tem o propósito de assessorar governos que acompanham, congelam e recuperam fundos desviados por corrupção.

A cargo da Corporação Financeira Internacional (CFI), assessora governos de países do Sul e do Leste a reformarem leis e mecanismos de regulação econômica. Tem como doadores a União Europeia e agências bilaterais da Europa, EUA, Canadá, Austrália e Nova Zelândia.

Fundos administrados pelo Banco para financiar programas e projetos voltados para aspectos ambientais, em particular o carbono. Recebem recursos de 16 Estados e 66 empresas privadas de diversos setores que totalizam mais de US\$6 bilhões.

Criada em novembro de 1999 para fomentar a capacidade de formulação estatística e harmonizar a sua utilização. Fundada pelo Banco Mundial e outros parceiros, envolve uma quantidade gigantesca de entidades públicas e privadas, multilaterais e bilaterais.

Criado em 2008 com a missão de arrecadar contribuições de doadores bilaterais e multilaterais.

Fontes: Banco Mundial (2008, 2010). Disponível em: <http://go.worldbank.org/G7VSZBNMF0>. Acesso em: 27 mar. 2011. Elaboração do autor.

As duas tabelas anteriores evidenciam a extensão da malha de relações construída pelo Banco. No plano internacional, ela abarca fundações privadas, ONGs, instituições de pesquisa, corporações privadas, instituições financeiras internacionais e organizações bilaterais e multilaterais financeiras e de assistência ao desenvolvimento. Essa rede de relações internacionais, por sua vez, articula-se com relações igualmente vastas e diversificadas, forjadas pelo Banco dentro de cada país cliente, potencializando enormemente a sua capilaridade social e sua influência política. 
Embora o Banco empreste apenas para o setor público, o mundo privado dos negócios tem entrada direta no funcionamento de suas operações. Isso ocorre porque financiamentos concedidos pelo Banco anualmente geram em torno de quarenta mil contratos que envolvem um grande volume de compra e venda de bens e serviços de todo tipo, parte dos quais por meio de licitações internacionais abertas a empresas sediadas nos Estados-membros. Historicamente, as empresas estabelecidas nos países capitalistas mais industrializados abocanham a maioria esmagadora dos contratos, graças a lobbies bem organizados e silenciosos, que contam com o apoio ativo de seus respectivos governos (Woods, 2006, p. 203). O mesmo vale para os serviços de consultoria privada contratados pelo Banco.

Malgrado a pregação sobre a natureza estritamente técnica de seu trabalho, historicamente a atuação do Banco Mundial tem uma dimensão política bem definida, resultante das prioridades estabelecidas pelos seus membros mais poderosos, em particular pelos EUA. Há muitas formas de discutir esse assunto. Aqui a abordagem enfatizará o papel intelectual do Banco como organizador e disseminador de determinadas visões sobre economia internacional, políticas de desenvolvimento e gestão pública.

\section{FORMAÇÃO DE QUADROS PARA O APARELHO DE ESTADO E CONSTRUÇÃO INSTITUCIONAL}

Um passo importante na estruturação do papel intelectual do Banco se deu em 1955, com a criação do Instituto de Desenvolvimento Econômico (IDE). Graças ao financiamento e ao apoio político das fundações Ford e Rockefeller, o IDE logo passou a disseminar ideias geradas pelo mainstream - e, com o tempo, pelo próprio Banco - para quadros políticos e técnicos graduados nos países clientes.

Intimamente articulado à construção institucional, o trabalho do IDE procurava não apenas formar quadros técnicos segundo uma determinada visão de Estado, gestão pública e desenvolvimento, mas também favorecer a montagem de agências domésticas estatais e paraestatais que pudessem assimilar e aplicar as ideias veiculadas pelo Banco (Stern; Ferreira, 1997, p. 526).

Os cursos oferecidos tinham como especialidade a gestão da política econômica e, sobretudo, a preparação e execução de programas e projetos de infraestrutura e energia (grandes hidroelétricas). No início, os cursos aconteciam em Washington, com duração de seis meses e voltados para quadros do alto escalão da burocracia dos Estados-membros. Nos anos seguintes, começaram a treinar também quadros de médio escalão para a elaboração de projetos e de estratégias de longo prazo para empréstimos. Os Estados, normalmente por meio do Banco Central ou do Ministério da Fazenda ou do Planejamento, deviam assegurar a remuneração integral dos alunos durante a realização dos estudos, bem como a sua recolocação ulterior em cargo equivalente ou superior ao que detinham antes da ida a Washington. Em 1971, mais de mil e trezentos funcionários já 
haviam passado pelo instituto. Como regra, os ex-alunos do IDE ocuparam posições estratégicas nos seus países de origem, chegando, inclusive, aos cargos de primeiro-ministro, ministro da Fazenda e do Planejamento (Mason; Asher, 1973, p. 326-330).

Outra forma de atuação intelectual era por meio da organização e do envio de "missões técnicas" a certos países, compostas de especialistas e consultores do Banco - a maioria, norte-americanos e britânicos (idem, p. 68) - e de outras organizações internacionais. No geral, tais missões perseguiam dois objetivos combinados. O primeiro era identificar projetos que fossem bancáveis, convencer as autoridades domésticas a demandar empréstimos ao Banco para financiá-los e treinar quadros técnicos locais para esse mesmo fim. Ou seja, tratava-se não apenas de criar demanda para os seus próprios "serviços" financeiros e não financeiros, mas também educar e fidelizar atores domésticos capazes de sustentá-la no tempo.

O segundo objetivo era analisar a situação econômica geral do país, orientar medidas de política macroeconômica e setorial e definir um rol de projetos passíveis de financiamento. A primeira missão, realizada na Colômbia em 1949, deu origem a planos bastante abrangentes, que implicavam nível elevado de vigilância sobre a economia e articulação com autoridades nacionais por parte do Banco (Hayter, 1971, p. 107-119; Mason; Asher, 1973, p. 299-302), em parceria informal com o FMI (Polack, 1997, p. 477).

No conjunto, essas missões alcançaram um número expressivo de países e possessões coloniais entre 1949 e 1964 e tenderam, em graus variados, a ampliar a capacidade e os instrumentos de influência do Banco sobre as políticas domésticas dos países-membros da periferia. Internamente, tais missões contribuíram bastante para a ascensão dos economistas em face dos engenheiros (Stern; Ferreira, 1997, p. 598).

Uma terceira forma de atuação intelectual consistia na construção institucional (institutional building), frequentemente sob a forma de criação de agências paraestatais, financiadas por fora do orçamento público ordinário e compostas de quadros técnicos e políticos altamente qualificados (Mason; Asher, 1973, p. 701-702). Organizadas para planejar e executar projetos financiáveis pelo Banco e influenciar o processo de tomada de decisão governamental, operavam nos níveis nacional, setorial ou de administração de projetos.

Tais agências, invariavelmente, estampavam o selo da neutralidade técnica atribuído pelo Banco, segundo o qual supostamente atuariam em prol do desenvolvimento de forma insulada de pressões políticas. Por meio desse mecanismo, o Banco formou uma rede estável e fiel de quadros técnicos e políticos e organismos no interior da administração pública de inúmeros países apta a responder aos seus requerimentos imediatos e estratégicos, na maioria dos casos passando por fora do controle parlamentar e com relativa independência em relação aos governos de plantão.

Em geral, tais agências davam origem a verdadeiras "ilhas de excelência", fomentando a balcanização da burocracia estatal. Em vários países, a malha de 
aparelhos técnico-gerenciais responsável por investimentos em setores inteiros da economia foi construída, precisamente, por meio desse tipo de "assistência técnica” (Rich, 1994, p. 75).

\section{A ESTRUTURAÇÃO DO TRABALHO DE PESQUISA E O NASCIMENTO DA “POBRETOLOGIA”}

A pesquisa propriamente dita passou a ocupar um lugar de destaque a partir dos anos de 1970. Até então, o Departamento de Economia do Banco Mundial, responsável pela atividade de investigação, havia sido "pequeno e subfinanciado", com pouca ou nenhuma influência sobre o âmbito operacional (Mason; Asher, 1973, p. 467). Ou seja, pode-se afirmar que até aquele momento o Banco atuara muito mais como uma caixa de ressonância de ideias produzidas pelo mainstream do que como um ator ativo e relevante em pesquisa econômica no cenário internacional.

Essa condição começou a mudar no início da gestão de Robert McNamara(1968-1981), que promoveu mudanças profundas na instituição. McNamara havia estudado e lecionado na Harvard Business School, presidido a Ford Motor Company e integrado o conselho consultivo da Fundação Ford. Indicado para o cargo de secretário de Defesa dos EUA por Kennedy, em 1961, e mantido por Johnson, assumira um papel central na atuação dos EUA na Guerra do Vietnã. Se, antes de sua chegada, o Banco era "quase um apêndice do Tesouro dos EUA" (Ayres, 1983, p. 7), com ele a instituição foi conduzida pela trilha da diplomacia do desenvolvimento.

Os impactos da Guerra do Vietnã sobre a política externa estadunidense influenciaram fortemente a gestão McNamara desde o seu início. À medida que crescia o dissenso doméstico em relação à política externa, erodiam-se as bases de apoio da assistência bilateral ao desenvolvimento no âmbito doméstico (Gwin, 1997, p. 210-212).

A gestão McNamara operou nesse contexto e o objetivo de consolidar o Banco como uma "agência de desenvolvimento" foi, em larga medida, uma resposta àquela situação. Os EUA apoiaram esse movimento. No final da década de 1960 e início da seguinte, cresceu a convicção em Washington de que era necessário aumentar a assistência multilateral diante da ajuda bilateral. Afinal, ainda que a assistência multilateral tivesse aumentado quatro vezes durante o Governo Kennedy, ela totalizava menos de dez por cento do total da ajuda externa norte-americana no final da década de 1960 .

Para Washington, o Banco Mundial e os demais bancos multilaterais de desenvolvimento (BMDs) poderiam alavancar fundos para os países da periferia importantes do ponto de vista geopolítico, sem desgastar ainda mais o apoio doméstico à assistência internacional. Ademais, a roupagem multilateral permitiria aos EUA despolitizar a assistência externa e evitar tensões diretas com governos, como poderia ocorrer pela via bilateral.

A ênfase na assistência multilateral também aliviaria os custos da política externa norte-americana, num contexto de declínio relativo da posição dos 
EUA na economia internacional, deterioração da situação macroeconômica do país - recorde-se que, em 1968, houve o primeiro déficit na balança comercial estadunidense em quase noventa anos -, aumento da pobreza, do desemprego e das desigualdades raciais. Por fim, a roupagem multilateral dos BMDs permitiria a Washington contornar as críticas internas à Guerra do Vietnã e ao apoio dos EUA a golpes militares e regimes ditatoriais que se espalhavam por toda a periferia (Burbach; Flynn, 1982, p. 72-73). Assim, numa mensagem enviada ao Congresso em setembro de 1970, o Governo Nixon propôs uma reorganização ampla do programa de ajuda bilateral e um reforço à ajuda multilateral.

O primeiro quinquênio da gestão McNamara foi marcado por uma reforma administrativa importante, que, entre outras inovações, criou o cargo de economista-chefe e equipou com recursos financeiros e humanos o departamento de pesquisa. McNamara convidou Hollis Chenery para assumir o novo cargo. Chenery havia trabalhado como economista na Europa durante o Plano Marshall, fora funcionário da USAID e também professor de economia nas universidades de Stanford e Harvard.

Para a formulação abrangente de políticas, o departamento chefiado por Chenery tinha a missão de estabelecer uma base sólida de dados e conceitos que desse suporte e respaldo à expansão agressiva das operações financeiras do Banco do ponto de vista geográfico e setorial, a fim de ampliar o seu raio de influência nos governos da periferia do sistema internacional na turbulenta conjuntura do final dos anos de 1960 e início dos de 1970 (Pereira, 2010b, cap. 4).

Em pouco tempo surgiu um conjunto crescente e regular de publicações próprias especializadas e voltadas não apenas para a construção de indicadores econômicos e sociais que se tornariam referências obrigatórias para pesquisadores e gestores públicos nos Estados clientes, mas também para a definição dos grandes desafios do desenvolvimento, entre os quais a redução da pobreza, tema que o Banco trabalharia para erguer como legítimo no âmbito da teoria econômica e central no âmbito das políticas sociais.

A "luta contra a pobreza" tinha raízes diretas nas injunções da Guerra Fria e foi enxertada no Banco pelo governo norte-americano (Kapur, Lewis; Webb, 1997, p. 222). Somados à derrocada dos EUA no Vietnã, outros acontecimentos ocorridos durante o quinquênio 1968-1973 empurraram o governo estadunidense e seus aliados mais próximos a buscarem novas estratégias de atuação, pressionando as organizações que integravam a sua rede de poder externo, como o Banco Mundial, a fazerem o mesmo. A lista é longa: eleição, governo e derrubada de Allende no Chile, eleição de Indira Gandhi, guerra entre Índia e Paquistão e fundação de Bangladesh, nacionalização do petróleo e reforma agrária no Peru, entre outros (idem, p. 251-252).

Em todos os casos, políticas de cunho distributivo e redistributivo eram objeto de forte apelo popular - com frequência embaladas pelo nacionalismo - e o fiel da balança era, na leitura do establishment norte-americano, o campesinato. Por essa razão, ganhar o apoio desse segmento ou, pelo menos, desativar o seu protesto social era considerado prioritário (Goldman, 2005, p. 68-69). As palavras de Samuel 
Huntington, em seu clássico da teoria da modernização publicado originalmente em 1968, resumem bastante bem essa visão:

Para o sistema político, a oposição dentro da cidade pode ser perturbadora, mas não é letal. A oposição no interior é, porém, fatal. Quem controla o interior controla o país. [...] Se os camponeses aceitam e se identificam com o sistema existente, isso proporciona uma base estável ao sistema. Se os camponeses se opõem ativamente ao sistema, passam a ser os portadores da revolução [...]. O camponês pode, assim, desempenhar um papel altamente conservador ou altamente revolucionário. (Huntington, 1975, p. 302)

Daí o lançamento, em 1973, do programa de desenvolvimento rural, baseado na estratificação da pobreza em duas categorias (relativa e absoluta) e na identificação de "focos de pobreza" (absoluta) no meio rural, que deveriam então ser "atacados" mediante projetos de financiamento para que pequenos agricultores aumentassem a produtividade da terra com a aplicação de técnicas de ponta e insumos industriais (McNamara, 1973). Ou seja, nada mais do que uma "pequena Revolução Verde" em parcelas do subsetor camponês, a fim de integrá-lo à atividade agrícola comercial, como forma de esvaziar o protesto social no campo e desenvolver a agricultura capitalista (Feder, 1976, p. 793-794).

Tais projetos tinham como pressuposto a aceitação das condições existentes em matéria de estrutura agrária. A concentração da propriedade da terra - fator elementar de determinação da pobreza e desigualdade social no meio rural - foi tomada como um dado ao qual os projetos deveriam se acomodar (Ayres, 1983, p. 104). Por isso, o itinerário proposto por $\mathrm{McNamara}$ constituía uma alternativa conservadora à reforma agrária redistributiva.

Dois anos depois, McNamara lançou o programa de desenvolvimento urbano com o objetivo de reduzir a pobreza urbana - "absoluta", sempre - e baseado nas mesmas premissas políticas:

Historicamente, a violência e os distúrbios civis são mais comuns nas cidades que no âmbito rural. Entre os grupos urbanos de baixa renda, as frustrações se inflamam e são facilmente aproveitadas pelos extremistas políticos. Se as cidades não começarem a tratar de maneira mais construtiva o problema da pobreza, esta pode muito bem começar a tratar de maneira mais destrutiva as cidades. Este não é um problema que admita demora por razões políticas. (McNamara, 1975, p. 36)

Convertida em imperativo político, a ideia de "redução da pobreza" foi academizada por sucessivos estudos e publicações do Banco, a começar pela obra coordenada por Hollis Chenery (1976), dando origem a uma espécie de "pobretologia" (Kay, 2006, p. 457), i.e., à imposição da pobreza como unidade de análise, parâmetro legítimo e foco obrigatório para toda e qualquer iniciativa no âmbito da assistência ao desenvolvimento. 
A institucionalização da "redução da pobreza" como parte da agenda internacional esteve diretamente ligada ao envolvimento cada vez maior do Banco em pesquisa (em particular, análises de inputs-outputs e custo-benefício), disseminação de informação e produção e compilação de dados. O Banco também passou a financiar a pesquisa local e a educar técnicos para fins de produção de dados e desenho de projetos ligados ao tema (Finnemore, 1997, p. 208; Goldman, 2005, p. 77-81).

$\mathrm{O}$ alargamento do campo de estudos dedicado a essa temática alimentou a gradativa imposição e legitimação de um novo vocabulário (centrado em termos como eficiência, mercado, renda, ativos, vulnerabilidade, pobre etc.), em detrimento de outro (como igualdade, exploração, dominação, classe, luta de classe, trabalhador etc.). Enfim, não apenas se estabeleceu um modo de interpretar e categorizar a realidade e a questão social, como também se desenhou uma nova agenda político-intelectual ancorada na "ciência da pobreza" e na "gestão política da pobreza" pela via da concessão de crédito, e não propriamente da filantropia, ainda que $\mathrm{McNamara}$ acionasse a retórica filantrópica da "ajuda aos pobres" com frequência (Pereira, 2010a).

A ideia de que a superação da pobreza aconteceria, fundamentalmente, pelo aumento da "produtividade dos pobres", no campo e na cidade, tinha como premissa a compreensão de que vivia em condições de pobreza apenas quem não estivesse inserido em atividades consideradas produtivas. Tal proposição operava um triplo movimento: primeiro, apagava o caráter desigual e combinado das formas de exploração e, portanto, a "funcionalidade dos pobres" (subempregados, pequenos agricultores etc.) para a acumulação capitalista; segundo, isolava a pobreza do conjunto das relações sociais como se ela fosse um fenômeno em si mesmo; terceiro, reificava as modalidades mais predatórias de desenvolvimento capitalista, na medida em que explicava a pobreza como exclusão do progresso, e não como um dos seus resultados (Assmann, 1980, p. 47; Payer, 1980, p. 140).

Esse triplo movimento permitiu ao Banco fortalecer politicamente a consigna da luta contra a pobreza, ao fazê-la parecer autoexplicativa e legítima por si própria. Permitiu também eludir a questão dos baixos salários e da necessidade de criação de empregos, uma vez que deslocava o foco de análise para a qualidade da inserção atomizada dos indivíduos no mercado.

\section{A CRIAÇÃO DO GRUPO CONSULTIVO PARA A PESQUISA AGRÍCOLA INTERNACIONAL (CGIAR)}

Em seu movimento expansivo, uma das ações mais importantes do Banco durante o primeiro quinquênio de McNamara foi a criação do Grupo Consultivo para a Pesquisa Agrícola Internacional (CGIAR), em maio de 1971. A iniciativa começou quando, no início de 1969, as fundações Ford e Rockefeller promoveram uma série de conferências bilaterais e multilaterais de agências de assistência com o objetivo de criar uma rede internacional de centros de pesquisa agrícola para impulsionar a difusão da Revolução Verde pelo mundo (Kapur; Lewis; Webb, 1997, p. 399; Mason; Asher, 1973, p. 574). 
Os quatro centros internacionais de pesquisa agrícola criados pelas duas fundações durante os anos de 1960 - o Instituto Internacional de Investigação sobre o Arroz (IRRI) nas Filipinas, o Centro Internacional de Melhoramento de Milho e Trigo (CIMMYT) no México, o Instituto Internacional de Agricultura Tropical (IITA) na Nigéria e o Centro Latino-Americano para Agricultura Tropical (CIAT) na Colômbia - formaram os pilares iniciais do CGIAR, que rapidamente se expandiu com a criação de novos centros. $\mathrm{O}$ Banco se apressou para encabeçar a iniciativa, desempenhando um papel de liderança política e intelectual desde então. De imediato, o novo sistema ganhou forte apoio público e privado. A USAID se tornou responsável por um quarto do total dos fundos e o Banco Mundial por dez por cento dos recursos.

As pesquisas sobre a primeira geração das variedades de trigo e arroz de alto grau de resposta produzidas pelo CIMMYT e pelo IRRI saíram no início dos anos de 1970 e serviram para estimular a difusão do plantio. Os resultados excepcionais de algumas colheitas reforçaram a ideia de que investir no CGIAR era um negócio altamente lucrativo (Kapur; Lewis; Webb, 1997, p. 401).

Articulado com seus parceiros bilaterais, o Banco estimulou os Estados clientes a criarem centros de investigação agropecuária em toda a periferia. A produção das novas variedades dependia de um sofisticado sistema de irrigação e da utilização de insumos industriais cuja eficiência máxima se dava a partir de certa escala, o que beneficiava os produtores mais ricos, mais instruídos e detentores das melhores terras (George, 1978, p. 111; Lappé; Collins, 1982, p. 115-122). O acesso ao crédito agrícola e a serviços de assistência técnica tornou-se indispensável aos produtores. Para viabilizá-lo, fundos públicos nacionais e estrangeiros cada vez mais vultosos passaram a ser canalizados diretamente para a produção das novas variedades de alto grau de resposta.

Como mostrou Goldman (2005, p. 86-87), a malha de instituições vinculadas ao CGIAR rapidamente se ampliou e se ramificou pelos âmbitos da ciência, das agências de assistência bilateral e multilateral e das corporações agroindustriais, dando origem a um complexo de poder baseado em um tipo específico de produção de conhecimento, baseado na articulação entre ciência, empresas e Estados. Milhares de técnicos e cientistas passaram a ser educados pelo sistema CGIAR e muitos deles ocuparam posições de destaque como ministros de Estado e membros de diretorias de centros de pesquisa e empresa multinacionais.

O intercâmbio promovido pelo CGIAR começou a carrear dólares para os institutos nacionais de pesquisa por meio de parcerias com universidades norte-americanas, impulsionando a norte-americanização dos sistemas agroalimentares nacionais, de leis de propriedade e leis de comércio e investimento nos países clientes. Essa rede ajudou a expandir os ramos industriais ligados à Revolução Verde (como energia, fertilizantes, pesticidas químicos, sementes sintéticas, maquinário agrícola etc.).

A pesquisa interna acompanhou esse movimento e lhe deu suporte, escorando e legitimando intelectualmente as prescrições do Banco em matéria de política 
econômica, setorial e social. Com a ascensão de Thatcher e Reagan no plano político e a revolução neoclássica no âmbito do pensamento econômico, expoentes da velha geração da economia do desenvolvimento (development economics) perderam espaço para nomes afinados com o novo mainstream. Símbolo maior do genocídio político da velha geração foi a substituição de Hollis Chenery, economista-chefe do Banco desde 1970, por Anne Krueger em 1982 (Dezalay; Garth, 2005, p. 147; Escobar, 1996, p. 177-186; George; Sabelli, 1996, p. 163-175; Goldman, 2005, p. 91-92; Kapur; Lewis; Webb, 1997, p. 338-339).

\section{ENQUADRAMENTO INTERNO DA PESQUISA E REPRODUÇÃO INTELECTUAL NO INÍCIO DA DÉCADA DE 1990}

$\mathrm{O}$ atrelamento da atividade de pesquisa à pauta política impulsionada pelo Banco marca o conjunto da sua produção intelectual, contrariando o discurso de suposta neutralidade técnica veiculado pela instituição. Um dos episódios mais reveladores desse atrelamento foi a elaboração da versão do Banco sobre o desenvolvimento industrial acelerado e prolongado dos países do leste da Ásia (Banco Mundial, 1993).

A preparação do estudo foi objeto de uma intensa disputa entre a ortodoxia neoliberal, comandada pelos EUA, e a proposta de desenvolvimento capitalista "orientado pelo Estado", encabeçada pelo Japão - na época a maior economia industrial do mundo e o segundo maior acionista do Banco e do FMI (Amsden, 1994, p. 630-631). De acordo com os dirigentes japoneses, o sucesso do capitalismo nipônico e de países como Taiwan e Coreia do Sul se sustentava, em particular, na forte regulação sobre o setor financeiro e numa política industrial cujo sistema de incentivos incluía, entre outros componentes, crédito público subsidiado a indústrias estratégicas intensivas em tecnologia.

$\mathrm{Na}$ virada da década, o Japão não apenas estava ampliando a sua gravitação política e econômica na Ásia, como pretendia fazer do seu enfoque o modelo para a transição da Rússia ao capitalismo, na tentativa de se tornar uma força política à altura da sua projeção econômica.

As receitas japonesas questionavam a doutrina e plataforma política do Banco sobre o papel do Estado e do mercado no crescimento econômico, centradas na defesa da completa liberalização financeira e da privatização de empresas públicas dos setores industrial e de serviços. Na verdade, porém, o desafio do Japão ao Banco era, fundamentalmente, um desafio aos EUA, dado que as ideias do Banco derivavam em grande parte do interesse norte-americano pelo livre mercado (Wade, 1997, p. 352).

O governo japonês criticou abertamente a orientação neoliberal do Banco e pressionou a diretoria executiva da entidade para que considerasse a experiência do leste e do sudeste asiáticos, solicitando a realização de um estudo específico sobre o tema. O Banco só cedeu depois de o governo japonês se comprometer a financiar o estudo (que custou US\$2,2 milhões) e retirar a sua oposição a uma diretriz do 
Banco, em formulação, que preconizava a desregulação financeira em grande escala (idem, p. 367).

O trabalho começou no início de 1992 e foi supervisionado por Lawrence Summers (então economista-chefe do Banco e atual conselheiro assessor econômico do presidente Barack Obama) e Nancy Birdsall (diretora norte-americana do Departamento de Investigação), que designaram o norte-americano John Page (doutor em economia pela Universidade de Oxford) como chefe de uma equipe de seis economistas, todos com doutorado em economia em universidades anglo-americanas. Nenhum dos envolvidos havia trabalhado na Ásia. Estudos de caso complementares ficaram a cargo da vice-presidência do Banco para o leste asiático, chefiada pelo indiano Vinod Thomas, doutor em economia pela Universidade de Chicago (idem, p. 369-370).

O estudo foi divulgado em setembro de 1993, durante a reunião anual conjunta do FMI e do Banco Mundial, e causou forte repercussão internacional. Entre as primeiras versões e o resultado final, houve um processo de depuração e alinhamento teórico-ideológico, em grande medida conduzido pela vice-presidência para o leste asiático (idem, p. 368-375). O informe manipulava uma falsa dualidade - livre mercado versus intervencionismo estatal - perante a qual o enfoque "amigável com o mercado" (market-friendly approach) propugnado pelo Banco desde 1991 parecia um constructo intermediário e equilibrado.

O relatório reconheceu, com inúmeras ressalvas, a importância estratégica do planejamento e ação estatais na orientação e sustentação do crescimento industrial naqueles países, mediante políticas setoriais ativas, concessão seletiva de crédito subsidiado, acordos entre agências governamentais e empresas privadas, protecionismo comercial seletivo, regulação da conta capital e poupança interna forçada. Porém, sustentou que tais intervenções haviam funcionado porque não foram "excessivas".

Além disso, insistiu no caráter específico daquela experiência, advertindo que não estava "demonstrado" que aquele rol de políticas poderia ser replicado em outras regiões. Sugeriu, também, que os êxitos econômicos seriam alcançáveis sem aquele tipo de ação estatal e que se deviam mais à orientação exportadora da economia que a modalidades específicas de ação pública. Ao final, ironicamente, aquela experiência foi apresentada como o resultado da combinação sui generis da teoria neoclássica com o enfoque "amistoso com o mercado".

Para além do debate sobre o informe e sua consistência científica para explicar a trajetória daquelas economias, o episódio alimentou a discussão sobre a qualidade da pesquisa produzida pelo Banco Mundial. Nessa direção, um dos primeiros a debater abertamente os mecanismos internos pelos quais o Banco subordinava e enquadrava a atividade de pesquisa à linha político-ideológica ditada por Washington foi Robert Wade, que trabalhou no Banco entre 1984 e 1988. O autor identificou cinco mecanismos principais de subordinação e enquadramento.

Em primeiro lugar, o tipo de fontes utilizadas: na maioria, estudos do próprio Banco, de consultores externos por ele financiados ou da fatia da academia anglo-americana partidária da economia neoclássica. 
Em segundo lugar, a parcialidade e a manipulação no tratamento dos dados estatísticos para "comprovar" conclusões definidas a priori, afinadas com a plataforma político-econômica neoliberal.

Em terceiro lugar, a formação e seleção do seu pessoal: apesar da pluralidade de nacionalidades, aproximadamente oitenta por cento do stafferam formados por universidades norte-americanas e britânicas inclinadas à economia neoclássica, cujas premissas supostamente autorizariam qualquer economista nelas apoiado a opinar sobre um país ou uma região baseado no domínio de alguns poucos "dados" e "variáveis".

Em quarto lugar, o processo de revisão editorial hierarquicamente organizado, ao longo do qual o que fugia à doutrina ou à prescrição política principal era descartado imediatamente.

Em quinto lugar, a centralidade dos valores e interesses norte-americanos no funcionamento do Banco, derivada da sua dependência perante os mercados financeiros internacionais e da "congruência autovalidante entre os valores dos donos e administradores do capital financeiro e os do Estado norte-americano" (Wade, 1997, p. 386). No geral, enfim, o episódio mostrou que a agenda de pesquisa do Banco era largamente instrumentalizada para dar substância às prescrições políticas afinadas com o programa neoliberal.

Àquela altura, em meados dos anos de 1990, com uma carteira anual de empréstimos que girava em torno de US $\$ 17$ bilhões, o Banco empregava cerca de oitocentos economistas profissionais e destinava aproximadamente US $\$ 25$ milhões ao ano para pesquisa, quantia muito superior ao orçamento de qualquer instituição pública de pesquisa econômica (Stern; Ferreira, 1997, p. 524). Parte significativa desses recursos era gasta com a contratação de consultores externos, em particular norte-americanos e ingleses, no disputadíssimo mercado internacional de consultorias privadas, no qual um contrato de trabalho para o Banco funcionava como passaporte para outros contratos, sempre bem remunerados em dólar. Uma carreira promissora em Washington muitas vezes podia começar com um contrato com o Banco para a redação de um paper.

A pesquisa era realizada pela equipe de investigação, mas envolvia também a equipe operacional, responsável pela relação com os governos. À equipe de pesquisa cabia criar ideias relativas ao desenvolvimento, estimular ideias concebidas fora do Banco, promovê-las, disseminá-las e, sobretudo, aplicá-las. Ou seja, além da elaboração de projetos e programas de investigação, cuja interface com o universo acadêmico era mais direta, a equipe de pesquisa também atuava com a equipe de operações nos acordos de empréstimo, na mediação de agências internacionais e governos e no diálogo sobre políticas com os Estados clientes (idem, p. 525).

A pressão permanente por realizar acordos de empréstimo - em particular aqueles para ajustamento estrutural, então no auge - funcionava como um fator de constrangimento e enquadramento da atividade de pesquisa. A avaliação de Stern e Ferreira (1997, p. 594) também reconheceu esse fato elementar. Nas suas próprias palavras: 
Em uma instituição orientada para operações, os pesquisadores não são livres para seguir inspiração intelectual. Eles estão sob constrangimentos de prioridades definidas e de uma necessidade clara de serem imediatamente úteis às operações. Além disso, há forte hierarquia e uma atmosfera muito mais reverencial do que nas universidades. Entre os pesquisadores existe uma preocupação considerável com o que seus superiores pensarão sobre as conclusões obtidas. (idem, ibidem)

Não surpreende, assim, que poucos dos trinta e um entrevistados pelos autores entre 1990-1992 (todos altos funcionários do Banco) vissem a instituição como tendo um papel importante de liderança intelectual no âmbito da pesquisa mundialmente dominante em economia. ${ }^{3}$ Em contraposição, muitos deles consideravam que o Banco desempenhava um papel importante em destilar ideias e conceitos para a formulação e execução de políticas nos países prestatários (idem, p. 597). Depois de mais de vinte anos envolvido intensamente na atividade de pesquisa, o seu papel como criador de conhecimento na área econômica foi considerado "modesto" (idem, p. 609).

A mesma opinião foi dada na época por Michael Gavin e Dani Rodrik (1995, p. 333): “É difícil localizar uma única ideia ou método importante em economia do desenvolvimento que tenha sido originada no Banco". Ou seja, o Banco se distinguia mais pela difusão de ideias econômicas produzidas pelo mainstream que propriamente pela criação delas.

\section{ENQUADRAMENTO INTERNO DA PESQUISA E REPRODUÇÃO INTELECTUAL EM MEADOS DA DÉCADA DE 2000}

Após uma década sob a gestão de James Wolfensohn (1995-2005), sempre crescendo e fazendo mais, o Banco desfrutava de uma posição sem paralelo em matéria de influência intelectual, por várias razões. Apesar do histórico pouco animador quanto à criação de conhecimento em economia e ciências sociais, sua legitimidade como fonte de dados, afiançador e disseminador de ideias, formador de gestores públicos, produtor de análises comparativas e guia em matéria de políticas de desenvolvimento estava bem estabelecida. Suas publicações eram referências obrigatórias em cursos de economia no mundo inteiro.

Criado durante a gestão McNamara e editado anualmente desde 1978, a publicação estrela do Banco, o Relatório sobre o desenvolvimento mundial, era de longe a edição do gênero mais cara e mais citada no mundo. Para a elaboração de uma ampla e variada gama de pesquisas acadêmicas, a dependência em relação aos indicadores econômicos e sociais produzidos pelo Banco, em regime de quase monopólio, era incontornável. Por sua vez, as análises comparativas internacionais

3 Entre outros, foram entrevistados Robert McNamara, Hollis Chenery, Anne Krueger, Stanley Fischer, Michael Lipton, Ernest Stern, Lyn Squire e Vito Tanzi. 
feitas pelo Banco não tinham concorrência à altura no meio acadêmico. Como regra, as últimas publicações e resumos de imprensa da instituição eram tomados como referência autorizada pelos maiores jornais do planeta.

$\mathrm{Na}$ cobertura de diversos assuntos, a mídia dependia quase exclusivamente do Banco como fonte de dados econômicos e sociais. A mesma influência e dependência podia ser constatada entre formuladores de políticas e gestores públicos nos países da periferia (Goldman, 2005, p. 101-102). A produção intelectual do Banco também servia de orientação para agências bilaterais de assistência ao desenvolvimento, para os demais bancos multilaterais e para a própria Organização Mundial do Comércio (OMC) (Broad, 2007, p. 701-702).

Além disso, os cursos de formação e treinamento promovidos pelo Banco emitiam certificados que abriam as portas para o mercado internacional de consultorias, no topo do qual estava a própria instituição como grande contratante (Goldman, 2005, p. 2-3). Tais atividades tendiam a ser copiadas nos Estados-membros e serviam como modelo de formação, legitimando a institucionalização de um determinado padrão de profissionalização e marginalizando outros (idem, p. 230).

O Banco acionava o seu capital intelectual por meio do seu considerável programa de empréstimos e de sua posição única como mediador entre governos, agências bilaterais e multilaterais e o universo empresarial, com a qual organizava políticas e negócios. Com os Estados clientes, o trabalho de persuasão tendia a ser maior quanto mais afinada com a agenda do Banco e mais insulada das pressões do sistema político local fosse a equipe de governo (Woods, 2006, p. 5).

Para erguer essa blindagem e fortalecer frações políticas e intelectuais aliadas dentro do aparelho de Estado e na sociedade civil, era indispensável, entre outros expedientes, construir consentimento social em torno de determinados programas, ideias e práticas institucionais. Isso explica por que o Banco gastava tanto com pesquisa e publicidade. Em 2005, o orçamento para investigação era de US\$25,3 milhões, cerca de $2,5 \%$ do orçamento da instituição, acrescidos de mais US\$6,9 milhões fornecidos por trusts funds, normalmente financiados por agências bilaterais (Deaton et al.2006, p. 26-27). Além disso, o orçamento do Departamento de Assuntos Externos saltara de US $\$ 20$ milhões em 2000 para US\$34 milhões em 2005 (Broad, 2006, p. 411-412).

A atividade de pesquisa era realizada em todo o Banco, abarcando os departamentos regionais, as redes, o Instituto Banco Mundial e, sobretudo, a Vice-Presidência de Economia do Desenvolvimento (DEC). Com noventa e três pesquisadores em tempo integral e trinta funcionários de apoio, a DEC constituía o núcleo da investigação do Banco e era subordinada diretamente ao economista-chefe (Deaton et al., 2006, p. 25-28). O Gráfico 1 ilustra a organização dos grupos responsáveis pela realização de pesquisas dentro do Banco. 
Gráfico 1 - Grupos dentro do Banco Mundial que produzem pesquisa (maio 2006)

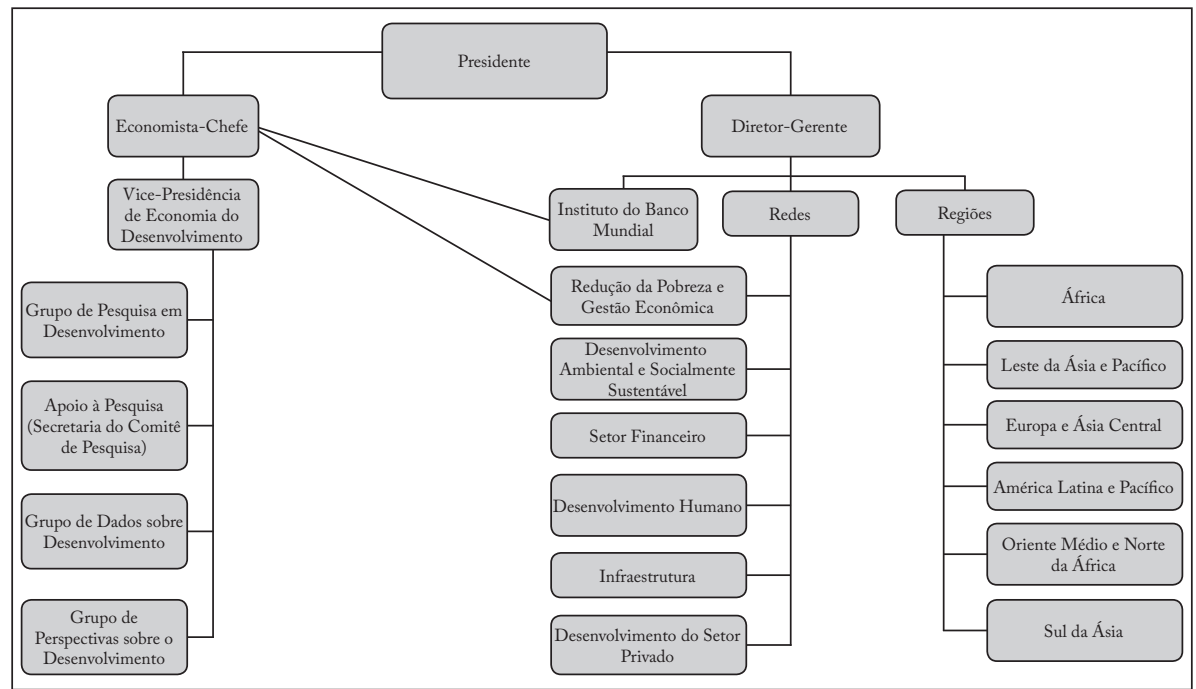

Fonte: Deaton et al., 2006, p. 25.

Elaboração do autor.

Como mostrou Robin Broad (2006), havia um sistema interno de recompensas e sanções que se reforçavam mutuamente para assegurar que a produção intelectual da DEC seguisse a linha política e ideológica do Banco e, assim, contribuísse para a manutenção do paradigma neoliberal. Um sistema informal, sutil, que funcionava de acordo com normas suaves e, quando necessário, passava por cima de regras formais. Um sistema cuja dinâmica minava o debate interno e afetava as conclusões das pesquisas, confirmando a priori as hipóteses neoliberais.

Segundo a autora, tal sistema estava estruturado por seis mecanismos. O primeiro deles era a forma de recrutamento ou contratação. Quase todos os funcionários, independentemente da nacionalidade, eram economistas ou tinham pós-graduação em economia, e a maioria esmagadora dos pesquisadores havia estudado nos Estados Unidos e/ou no Reino Unido. As fronteiras da disciplina e a inclinação à economia neoclássica demarcavam um perfil profissional específico, predisposto a "ressoar" o paradigma dominante. Muito pouco da pesquisa produzida pelo Banco envolvia investigadores de países da periferia (Deaton et al., 2006, p. 9).

O segundo mecanismo identificado por Broad era a promoção. Como a maioria dos empregados trabalhava com contratos de curto prazo, o maior objetivo de um investigador que desejasse fazer carreira no Banco era obter, depois de cinco anos, a regularização necessária à estabilidade no cargo. Um dos critérios avaliados era o número de publicações: os profissionais da DEC precisavam publicar não apenas dentro do Banco, mas também pelo menos dois artigos por ano em revistas de economia consideradas de excelência internacional. 
Outro critério avaliado era a capacidade de os pesquisadores obterem financiamento adicional no Comitê de Pesquisa e nos trusts funds. Esse dinheiro destinava-se a cobrir despesas com contratação de consultores externos, realização de seminários e conferências, disponibilização de dados on-line, viagens, entre outras. Sendo bem-sucedido na competição por fundos, o investigador conquistava prestígio e capacidade de alavancar novos recursos. Além disso, as avaliações também observavam a influência do investigador sobre as operações do Banco. Uma terça parte do tempo (treze semanas por ano) do investigador devia ser dedicada a apoiar o staff operacional, normalmente sob a forma de trabalho analítico ou assessoramento a países clientes.

Premido a realizar acordos de empréstimo no atacado, ao staff operacional interessava contar com investigadores que tivessem sintonia com suas atividades. $\mathrm{Ou}$ seja, enquanto os pesquisadores precisavam "vender" suas ideias para os operadores, a estes interessava "comprar" parte do tempo de trabalho de investigadores que os ajudassem a promover internamente as operações que comandavam. À mesma conclusão chegou Goldman (2005, p. 105-110).

$\mathrm{O}$ terceiro mecanismo identificado por Broad era o reforço seletivo das normas. A pesquisa que não tivesse a "ressonância" esperada era submetida a um processo mais rigoroso de avaliação interna e externa e, com frequência, era descartada. De acordo com um dos entrevistados, a avaliação das propostas de pesquisa dependia do tema do documento e de quem fosse o autor. "Se você for um economista neoclássico respeitado, [a aprovação] só precisa da assinatura do seu chefe. Se for crítico, você é submetido a revisões intermináveis até desistir" (Broad, 2006, p. 404). Evidentemente, esse tipo de mecanismo só poderia funcionar com eficácia dentro de uma organização fortemente hierarquizada. Entende-se, por isso, a observação de que havia pressão não apenas sobre os pesquisadores, mas também sobre seus superiores por parte da presidência do Banco e de outras altas instâncias. Tudo para que coisas diretamente contrárias à linha política do Banco não fossem ditas (Deaton et al., 2006, p. 20).

O desencorajamento do discurso dissonante era o quarto mecanismo. Admitia-se a crítica em questões marginais, mas não em aspectos centrais da agenda política do Banco ou do pensamento neoliberal. Aqueles que haviam levantado algum dissenso eram caracterizados como pessoas "inadaptadas", "iconoclastas" e "insatisfeitas", interessadas em perseguir tão somente suas próprias "idiossincrasias".

O quinto mecanismo era a manipulação de dados e conclusões. Broad citou exemplos de como o Banco havia alterado e manipulado resumos executivos e informes para a imprensa, jogando com o fato de que a maioria das pessoas, incluindo jornalistas de grandes meios de comunicação, costuma ler apenas comunicados resumidos. Em alguns casos, entre o resumo e o conteúdo do trabalho havia discordância integral.

O sexto e último mecanismo era a projeção externa. Cabia ao Departamento de Assuntos Externos, responsável pela publicidade do Banco, projetar certos trabalhos produzidos pela DEC por meio de um trabalho intenso de difusão nos 
âmbitos político, jornalístico e acadêmico. Com um orçamento milionário e contatos privilegiados nos grandes meios de comunicação, o departamento era capaz de promover lançamentos e coletivas de imprensa em várias cidades do mundo, projetando internacionalmente qualquer pesquisador em pouquíssimo tempo. Em troca, o departamento cobrava a sintonia entre o conteúdo da pesquisa e a linha político-intelectual do Banco.

No final da sua gestão, Wolfensohn encomendou a uma equipe de "notáveis" uma avaliação sobre a produção intelectual do Banco Mundial no período de 1998 a 2005. A equipe foi dirigida por Angus Deaton (Princeton) e integrada por Kenneth Rogoff (ex-economista-chefe do FMI e professor de Harvard), Abhijit Banerjee (Instituto de Tecnologia de Massachusetts - MIT), Nora Lustig (PNUD) e mais vinte e cinco pesquisadores, entre os quais Nancy Birdsall e Sebastián Edwards (ex-economista-chefe do Banco para a América Latina e o Caribe). O relatório foi concluído em setembro de 2006 e divulgado em janeiro de 2007. O foco da avaliação foi o trabalho da DEC. Analisou-se também a produção dos departamentos regionais e temáticos, do Instituto do Banco Mundial e da pesquisa contratada a consultores externos.

Uma avaliação com esse perfil só podia ter, como teve, limites óbvios. Ainda sim, o relatório repercutiu mal para o seu financiador. Afinal de contas, constatou-se que a maioria das publicações do Banco se baseava em fontes (primárias e secundárias) do próprio Banco, financiadas ou promovidas por ele. Um caso de narcisismo agudo, que às vezes chegava, segundo Deaton et al. (2006, p. 73), ao nível de "paródia". Além disso, destacou-se que a pesquisa era usada para "fazer proselitismo sobre as políticas do Banco, com frequência sem tomar uma visão balanceada das evidências e sem expressar o ceticismo adequado" (idem, p. 6), o que minaria a credibilidade e a própria utilidade da instituição como organismo de investigação científica.

\section{CONCLUSÃO}

O narcisismo agudo do Banco não difere do que ocorre em alguns setores e grupos do meio acadêmico e tem considerável eficácia político-intelectual. Enquanto um documento depende do outro para sua evidência e argumentação, um corpo interno de conhecimento é produzido e reforçado, amalgamando ideias e práticas e desencorajando o dissenso (Goldman, 2005, p. 131). Mais que isso, desencorajando a reflexividade crítica necessária ao trabalho intelectual, decorrente da liberdade inegociável para se questionar os pressupostos que dão fundamento à própria atividade científica (Bourdieu, 2001, p. 38).

Pesquisa e política são inseparáveis no cotidiano do Banco e a mediação entre elas é feita, sobretudo, pelo dinheiro. Se o Banco Mundial fosse apenas um intermediário financeiro, o seu staff atual de mais de dez mil funcionários poderia ser reduzido a apenas um décimo (Kapur, 2006, p. 159). Na verdade, o dinheiro sempre funcionou como instrumento para fazer circular, internalizar e 
institucionalizar o produto principal: ideias e prescrições políticas - produzidas ou avalizadas por ele - sobre o que fazer, como e para quem, em matéria de desenvolvimento capitalista.

A institucionalização de ideias e prescrições políticas exige, por sua vez, a criação, organização e a manutenção de um clima político e intelectual hospitaleiro pelo mundo afora, razão pela qual o Banco investe bastante em relações públicas, pesquisa, atividades de formação profissional e articulação com instituições internacionais, agências bilaterais, órgãos públicos e organizações nacionais privadas nos Estados-membros.

Os dados e mensagens que emite de Washington são disseminados por agências de notícias internacionais e costumam ser reproduzidos por grandes veículos nacionais de comunicação com força normativa. Além disso, nos países onde atua, o Banco teceu ao longo de décadas uma malha mais ou menos extensa e diversificada de relações em diversos âmbitos (político, empresarial, científico e social) que dá suporte à manutenção e à disseminação da sua influência. Para exercê-la e reproduzi-la em escala ampliada, o Banco precisou e precisa costurar relações para além dos limites de Washington.

A pesquisa foi e continua sendo um componente vital de toda essa engrenagem político-organizativa. Sem isso, o Banco não teria a autoridade e a gravitação que tem. Qualquer investigação acerca da sua influência no desenho de políticas setoriais nacionais e subnacionais passa, entre outros expedientes, pelo conhecimento sobre como operar essa engrenagem.

\section{REFERÊNCIAS}

Amsden, Alice. Why isn't the whole world experimenting with the East Asian model to develop? Review of The East Asian Miracle. World Development, London: Elsevier, v. 22, n. 4, p. 627-633, 1994.

Assmann, Hugo. El "progresismo conservador" del Banco Mundial. In:

(Ed.). Banco Mundial: un caso de "progresismo conservador". San José: Departamento Ecuménico de Investigaciones, 1980. p. 9-68.

Ayres, Robert. Banking on the poor: the World Bank and world poverty. London: MIT Press, 1983.

Banco Mundial. The East Asian miracle. Washington, DC: Oxford University Press, 1993.

. Relatório anual - volume I. Washington, DC: The World Bank, 2008.

Relatório anual - volume I. Washington, DC: The World Bank, 2010.

Bourdieu, Pierre. Contrafogos 2. Rio de Janeiro: Jorge Zahar, 2001. 
BROAD, Robin. Research, knowledge, and the art of "paradigm maintenance": the World Bank's Development Economics Vice-Presidency (DEC). Review of International Political Economy, London: Routledge, v. 13, n. 3, p. 387-419, 2006.

."Knowledge management": a case study of the World Bank's research department. Development in Practice, London: Routledge, v. 17, n. 4-5, p. 700-708, 2007.

Brzezinski, Zbigniew. El gran tablero mundial: la supremacia estadunidense y sus imperativos geoestratégicos. Barcelona: Paidós, 1998.

Burbach, Roger; Flynn, Barbara. Agroindústria nas Américas. Rio de Janeiro: Zahar, 1982.

Chenery, Hollis Burnley; Ahluwalia, Montek S.; Bell, C. L. G.; Duloy, John H.; Jolly, Richard et al. Redistribución con crecimiento; políticas para mejorar la distribución del ingreso em lós países em desarrollo em el contexto del crecimiento econômico. Madrid: Tecnos, 1976.

Deaton, Angus; Banerjee, Abhijit; Lustig, Nora; Rogoff, Ken et al. An evaluation of World Bank research, 1998-2005. Washington, DC: 24 sept. 2006. Disponível em: <http://go.worldbank.org/U6VB00O7X1>. Acesso em: 2 abr. 2011.

Dezalay, Yves; Garth, Bryant. La internacionalización de las luchas por el poder: la competencia entre abogados y economistas por transformar los Estados latinoamericanos. México, DF: Instituto de Investigaciones Jurídicas/Universidad Nacional Autónoma de México, 2005.

Escobar, Arturo. La invención del Tercer Mundo: construcción y deconstrucción del desarrollo. Bogotá: Editorial Norma, 1996.

Feder, Ernest. La pequena Revolución Verde de McNamara. El proyecto del Banco Mundial para la eliminación del campesinado del Tercer Mundo. Comercio Exterior, México, DF: v. 26, n. 7, p. 793-803, 1976.

Finnemore, Martha. Redefining development at the World Bank. In: Cooper, Frederick; PACKARD, Randall (Eds.). International development and the social sciences. Essays on the history and politics of knowledge. Berkeley: University of California Press, 1997.

Gavin, Michael; Rodrik, Dani. The World Bank in historical perspective. American Economic Review, Washington, DC: American Economic Association, v. 85, n. 2, p. 329-334, 1995.

George, Susan. O mercado da fome. Rio de Janeiro: Paz e Terra, 1978. .; SAbelli, Fabrizio. La religión del crédito: el Banco Mundial y su imperio secular. 2. ed. Barcelona: Intermón, 1996.

Goldman, Michael. Imperial nature: the World Bank and struggles for social justice in the age of globalization. New Haven/London: Yale University Press, 2005. 
Gwin, Catherine. U.S. relations with the World Bank, 1945-1992.In: Kapur, Devesh; Lewis, John P.; Weвв, Richard (Eds.). The World Bank: its first half century - history. Washington, DC: Brookings Institution Press, v. 2, 1997.p. 195-274.

Hayter, Teresa. Aid as imperialism. Baltmore: Penguin, 1971.

Huntington, Samuel. A ordem politica nas sociedades em mudança. São Paulo; Rio de Janeiro: Editora da USP/Forense Universitária, 1975.

Kapur, Devesh. The "knowledge" Bank. In: Birdsall, Nancy (Ed.). Rescuing the World Bank. Washington, DC: Center for Global Development, 2006.

Kapur, Devesh; Lewis, John P.; Weвb, Richard. The World Bank: its first half century - history. Washington, DC: Brookings Institution Press, v. 1, 1997.

Kay, Cristóbal. Rural poverty and development strategies in Latin America. Journal of Agrarian Change, London: Blackwell, v. 6, n. 4, p. 455-508, 2006.

Lappé, Frances Moore; Collins, Joseph. Comer és primero: más allá del mito de la escasez. México, DF: Siglo XXI, 1982.

McNamara, Robert. Discurso anual ante la Junta de Gobernadores. Nairóbi: The World Bank, 24 set. 1973.

Discurso anual ante la Junta de Gobernadores. Washington, DC: The World Bank, 1 set., 1975.

Mason, Edward; Asher, Robert. The World Bank since Bretton Woods. Washington, DC: The Brookings Institution, 1973.

Payer, Cheryl. El Banco Mundial y los pequeños agricultores. In: Assmann, Hugo (Ed.). Banco Mundial: un caso de "progresismo conservador". San José: Departamento Ecuménico de Investigaciones, 1980. p. 135-170.

Pereira, João Márcio Mendes. O Banco Mundial e a construção político-intelectual do combate à pobreza. Topoi, Rio de Janiero: UFRJ, v. 11, p. 260-282, 2010a. Disponível em: <http://www.revistatopoi.org/numeros_anteriores/topoi21/Topoi21_14Artigo14. pdf>. Acesso em: 2 abr. 2011.

. O Banco Mundial como ator politico, intelectual e financeiro (1944-2008). Rio de Janeiro: Civilização Brasileira, 2010b.

Polack, Jacques. The World Bank and the IMF: a changing relationship. In: Kapur, Devesh; Lewis, John P.; Weвв, Richard (Eds.). The World Bank: its first half century perspectives. Washington DC: Brookings Institution Press, v. 2, 1997. p. 473-521.

Rich, Bruce. Mortgaging the Earth: the World Bank, environmental impoverishment, and the crisis of development. Boston: Beacon Press, 1994.

Stern, Nicholas; Ferreira, Francisco. The World Bank as "intellectual actor”. In: Kapur, Devesh; Lewis, John P.; WeвB, Richard (Eds.). The World Bank: its first half century perspectives. Washington DC: Brookings Institution Press, v. 2, 1997.p. 523-610. 
Wade, Robert Hunter. Japón, el Banco Mundial y el arte del mantenimiento del paradigma: el Milagro del Este Asiático en perspectiva política. Desarrollo Económico, Buenos Aires: Instituto de Desarrollo Económico y Social,v.37, n. 147, p. 351-387, 1997.

Wolfensohn, James. New directions and new partnerships. Washington, DC: Address to the Board of Governors, The World Bank, oct. 10, 1995.

Woods, Ngaire. The globalizers: the IMF, the World Bank and their borrowers. Ithaca/ London: Cornell University Press, 2006.

\section{SOBRE O AUTOR}

João Márcio Mendes Pereira é doutor em história pela Universidade Federal Fluminense (UFF). Professor adjunto da Universidade Federal Rural do Rio de Janeiro (UFRRJ).

E-mail: joao_marcio1917@yahoo.com.br

Recebido em abril de 2011

Aprovado em fevereiro de 2012 


\section{JOÃO MÁRCIO MENDES PEREIRA}

\section{As ideias do poder e o poder das ideias: o Banco Mundial como ator político-intelectual}

Neste texto, discute-se como o Banco Mundial explora a sinergia entre empréstimos e pensamento econômico para ampliar a sua influência e institucionalizar sua pauta de políticas em âmbito internacional. Parte-se da hipótese de que o Banco age, desde as suas origens, ainda que de diferentes formas, como um ator político, intelectual e financeiro, em virtude de sua condição singular de emprestador, formulador e articulador de políticas e veiculador de ideias - produzidas pelo mainstream anglo-saxônico e disseminadas por ele ou produzidas por ele, em sintonia com o mainstream econômico - sobre o que fazer, como e para quem em matéria de desenvolvimento capitalista.

Palavras-chave: Banco Mundial; pensamento econômico; pesquisa científica; empréstimos; influência política. 


\section{Ideas of power and the power of ideas: the World Bank as a political-intellectual actor}

This article discusses how the World Bank explores the synergy between loans and economic thinking to increase its influence and institutionalize its policy agenda internationally. We start from the hypothesis that the Bank has acted, since its origins, even if in different ways, as a political, intellectual and financial actor due to its singular condition of lender, policy formulator and articulator, and propagandist of $i d e a s$ - produced by the anglo-saxon mainstream and disseminated or produced by the bank, in sync with this same economic mainstream - of what to do in terms of capitalist development, how to do it and to whom.

Keywords: World Bank; economic thinking; scientific research; loans; political influence.

\section{Las ideas del poder y el poder de las ideas: el Banco Mundial como actor político-intelectual}

Se discute cómo el Banco Mundial explota la sinergia entre los préstamos y el pensamiento económico para expandir su influencia e institucionalizar su agenda politica internacional. Se parte de la hipótesis de que el Banco, desde sus orígenes, aunque de diferentes maneras, actúa como un actor político, intelectual y financiero, debido a su condición de prestamista, formulador y articulador de politicas y difusor de ideas-producidas por mainstream anglosajón y difundido por él o producidas por él, de acuerdo con el mainstream económico-sobre qué hacer, cómo y para quién en lo que se refiere al desarrollo capitalista.

Palabras clave: Banco Mundial, pensamiento económico, investigación científica, préstamos, influencia politica. 